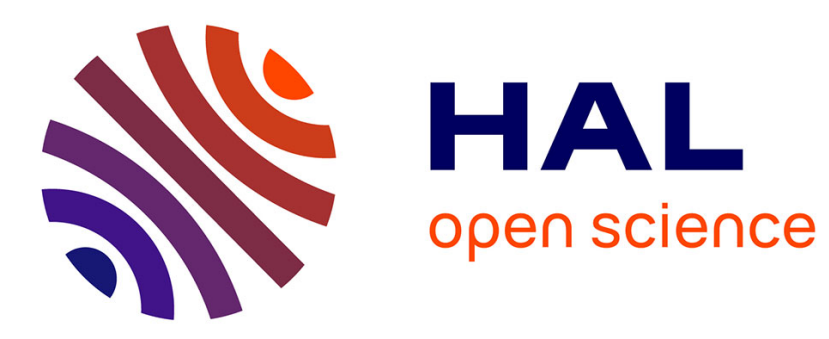

\title{
Incentives and Coordination in Vertically Related Energy Markets
}

Augusto Rupérez Micola, Albert Banal-Estañol, Derek W. Bunn

\section{To cite this version:}

Augusto Rupérez Micola, Albert Banal-Estañol, Derek W. Bunn. Incentives and Coordination in Vertically Related Energy Markets. Journal of Economic Behavior and Organization, 2008, 67 (2), pp.381. 10.1016/j.jebo.2006.12.007 . hal-00601887

\section{HAL Id: hal-00601887 https://hal.science/hal-00601887}

Submitted on 21 Jun 2011

HAL is a multi-disciplinary open access archive for the deposit and dissemination of scientific research documents, whether they are published or not. The documents may come from teaching and research institutions in France or abroad, or from public or private research centers.
L'archive ouverte pluridisciplinaire HAL, est destinée au dépôt et à la diffusion de documents scientifiques de niveau recherche, publiés ou non, émanant des établissements d'enseignement et de recherche français ou étrangers, des laboratoires publics ou privés. 


\section{Accepted Manuscript}

Title: Incentives and Coordination in Vertically Related Energy Markets

Authors: Augusto Rupérez Micola, Albert Banal-Estañol, Derek W. Bunn

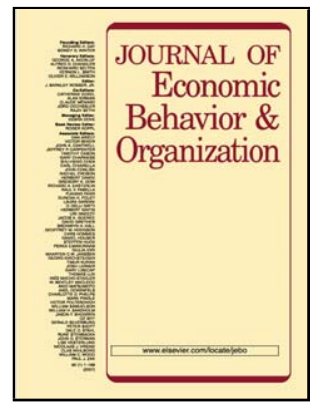

PII:

S0167-2681(08)00098-X

DOI: doi:10.1016/j.jebo.2006.12.007

Reference: JEBO 2209

To appear in: Journal of Economic Behavior \& Organization

Received date: $\quad$ 5-10-2005

Revised date: 24-11-2006

Accepted date: $\quad$ 4-12-2006

Please cite this article as: Micola, A.R., Banal-Estañol, A., Bunn, D.W., Incentives and Coordination in Vertically Related Energy Markets, Journal of Economic Behavior and Organization (2007), doi:10.1016/j.jebo.2006.12.007

This is a PDF file of an unedited manuscript that has been accepted for publication. As a service to our customers we are providing this early version of the manuscript. The manuscript will undergo copyediting, typesetting, and review of the resulting proof before it is published in its final form. Please note that during the production process errors may be discovered which could affect the content, and all legal disclaimers that apply to the journal pertain. 


\title{
Incentives and Coordination in Vertically Related Energy Markets*
}

\author{
Augusto Rupérez Micola ${ }^{\mathrm{a}} \quad$ Albert Banal-Estañol ${ }^{\mathrm{b} \dagger}$ \\ Derek W. Bunn ${ }^{\mathrm{c}}$ \\ ${ }^{\mathrm{a}}$ Department of Economics and Business, Universitat Pompeu Farbra \\ ${ }^{b}$ Department of Economics, City University \\ ${ }^{\mathrm{c}}$ Decision Sciences, London Business School
}

December 2006

\begin{abstract}
We present an agent-based model of a multi-tier energy market. We show how reward interdependence between strategic business units within a vertically integrated firm can increase its profits in oligopolistic energy markets. The effects are shown to be distinct from those of the raising rivals' costs model. In our case, higher prices relate to the nature of energy markets, which facilitate the emergence of financial netback effects.

Keywords: Agent-based modelling, energy markets, reward interdependence.

JEL codes: C63, L22, L97.
\end{abstract}

${ }^{*}$ We are grateful to Laurent David, Tobias Kretschmer, Olivier Massol, Phanish Puranam, Stéphane Tchung-Ming, Xavier Vives, the editors, Herbert Dawid and Giorgio Fagiolo, two anonymous referees, and seminar participants at the INFORMS-2004 conference (Denver), European Doctoral Research Conference (London), WEHIA-2005 (Colchester), ACEPOL-2005 (Bielefeld), Worskshop on Competition and Regulation (IESE, Barcelona), INFER Conference in Competition Policy in Network Industries (London), Gaz de France (Paris), Instituto de Empresa (Madrid), London Business School, Rotterdam School of Management and Unilever's Research Centre (Colworth, UK). Financial support from Gaz de France is gratefully acknowledged.

${ }^{\dagger}$ Corresponding author. Northampton Square, London EC1V 0HB, UK. Tel: +44 (0) 20 7040 4576; Fax: +44 (0) 207040 8580. E-mail: a.banal-estanol@city.ac.uk 


\section{Introduction}

This paper studies the vertical relationships between gas and electricity markets. Vertical relationships are those that involve an exchange between sequential stages of the value chain. In the energy industry, gas is an important input for electricity generation, and therefore wholesale natural gas and electricity markets are vertically interrelated. The same is true for wholesale and retail electricity markets since retailers buy electricity from wholesalers (Stern 1998).

Vertical interactions may involve separate firms or different strategic business units (SBUs) within the same firm (Gulati et al. 2005). Vertical integration is widespread among European energy firms. Gas producers often own gasfired power plants, and many electricity firms consist of generation and retail SBUs (Finon and Midttun 2004). Mergers between gas and electricity firms are relatively new in the United States, but they are occurring at a rapid pace (Hunger 2003). Moreover, the merger activity appears to be accelerating as competition opportunities expand, incentive regulation diffuses more widely, and regulators have become less hostile to mergers (Joskow 2000).

Several streams of literature have studied the advantages as well as the disadvantages of vertical integration. Industrial economists have extensively analysed whether vertically related firms could benefit from foreclosing nonintegrated rivals (see Rey and Tirole 2004 for a recent survey). ${ }^{1}$ Ordover et al. (1990), for example, show that a vertically integrated firm in a bilateral duopoly may benefit from disadvantaging its downstream rival. ${ }^{2}$ The argument runs as follows. If the upstream unit ceases to sell in the input market, its upstream rival will face less competition and raise prices. Higher input prices increase the costs of the non-integrated downstream rival. This firm is forced to reduce production and increase prices. As a result, the vertically integrated firm can increase profits by raising both its end-user market share and price. ${ }^{3}$

Studies of vertical relationships in energy markets (e.g. Granitz and Klein 1996, Bushnell et al. 2005) often explain their findings using this foreclosure argument. However, its logic depends crucially on the firm's ability either to internalise transactions or to set an internal transfer price that is different from the external (input) market price. In practice, wholesale energy markets are often compulsory, so trading internalisation is not feasible. Moreover, the standard energy market mechanism is the uniform price auction, which seems to

\footnotetext{
${ }^{1}$ Management scholars have identified several other motives for firms to integrate vertically (Harrigan 1984 and 1986), including the reduction of transaction costs (Williamson 1975, Mahoney 1992), the reduction of corporate risk (Chatterjee et al. 1992) and the elimination of the double marginalisation inefficiency (see e.g. Gaudet and van Long 1996).

${ }^{2}$ Salinger (1988), on the other hand, analyses whether vertical integration leads to higher or lower prices in a successive oligopoly setting.

${ }^{3}$ Ordover et al. assumed that the vertically integrated firm can commit to limit its supplies to the downstream rivals and that the upstream competitor can charge only linear prices. Several authors have relaxed some of their assumptions. In particular, Choi and Yi (2000) and Ma (1997) dispense in different settings with the commitment assumption, although not with the linear pricing one. Allowing for a broader set of tariffs, Hart and Tirole (1990) show that vertical integration may also benefit the integrated firms if the upstream unit is more efficient than its competitors.
} 
make differences between internal and external prices impossible at the outset. Thus, two of the main resting points of the foreclosure or raising rivals' costs logic are often not present in energy markets.

This paper introduces an agent-based simulation model of natural gas and electricity markets. We show how corporate incentives linking the strategic business units within a vertically integrated firm can increase prices in energy markets. The effects are shown to be different from those arising in the standard models of vertical foreclosure. In our case, higher prices are related to the existence of financial netback effects in energy markets.

Wholesale natural gas is often priced against wholesale electricity prices, which, in turn, are usually set with reference to retail tariffs. Industry players refer to this financial process as netback or spark spread pricing. The use of netback pricing is well documented in the energy markets literature (for an early discussion see Moxnes 1987) and suggests a sequential relationship between energy markets in which gas and electricity markets are cleared in a down-toupstream sequence. This is in contrast to the Ordover et al.'s "physical flow" formulation, widely adopted by the foreclosure literature, whereby upstream prices are determined before those downstream.

Trading is not a simple sequential procedure in most industry supply chains, as it is often iterative and tentative before deals are struck, so that modeling it either way is an abstraction. However, in the energy case, there are good reasons to support netback pricing rather than the physical flow formulation. First, retail prices are generally fixed for longer periods of time than upstream prices. For example, in the UK, retail consumers cannot change supplier during the first twenty eight days of signing a contract, but upstream prices vary every half hour. Therefore, retailers and generators take downstream prices as given when trading in the wholesale market. ${ }^{4}$ Second, electricity is non-storable, consumption and generation have to be balanced at all times, but end-users are free to choose volume. As a consequence, information on retail consumption volumes has to flow upwards in the supply chain via prices. ${ }^{5}$

In this context, it seems plausible that widely used vertical incentives should play a role on the determination of energy prices. The general reward system of an organisation influences the behavioural choices of its members. Bonuses tied to overall profits create incentives for cooperative behaviour both between individuals (Zander and Wolfe, 1964; Wageman and Baker, 1997) and across de-

\footnotetext{
${ }^{4}$ In contrast, in other markets, one can argue that upstream producers fix their prices before downstream firms compete. In the typical example of a producer and a retailer, the retailer buys from the producer and then competes in the downstream market. As such, the downstream firm would take the upstream price as given (the item is already bought).

${ }^{5}$ In practice there are several cycles of this. Ahead of real-time, retailers will make forecasts of demand and seek to contract power to cover it. Generators will make forecasts of output and purchase fuels to cover it. In real time, end-user demand is discretionary but at a preset fixed price. Retailers will have to cover imbalances between their contract and actual offtake at the spot electricity imbalance price, which is actually set slightly ex post depending upon what the system operator has to purchase in real time to ensure system stability. Similarly, there will be real-time energy balancing in the gas network adapting to what the power stations have had to do.
} 
partments within a firm (Petersen 1992, Kretschmer and Puranam forthcoming). For individuals, the more interdependent the task, the more interdependent the reward system should be (Wageman and Baker) because it results in a positive relationship between effectiveness of the integrative devices and organisational performance (Lawrence and Lorsch 1967). For firms, the importance of cooperation between SBUs grows with their interdependence (Gulati and Singh 1998) and the higher the inter-unit synergies, the more useful the collaborative incentives are (Kretschmer and Puranam). Collaborative incentives, however, not only encourage cooperation but may also enhance free riding. Indeed, rewards based on aggregate profits hinder the identification of individual performances. As a consequence, individuals have more incentives to shirk hoping that the others will compensate (Holmstrom 1982, Petersen 1992). ${ }^{6}$

Despite the importance of collaborative incentives, the existing literature provides no guidance as to how they should be given to sequential SBUs in vertically integrated energy firms. In order to fill this gap, we consider a setting consisting of two sequential, multiple-unit, compulsory, uniform-price auctions representing a wholesale and a retail energy market. Although quite realistic, this complex trading environment presents a manifold of non-Pareto ranked Nash equilibria (von der Fehr and Harbord 1993). To achieve predictions, we adopt an inductive selection method based on the adaptive theory of reinforcement learning put forward by Roth and Erev (1995).

The agent-based simulations show that coordination overcomes the potential disadvantages of broad collaborative incentives due to the large interdependences between energy markets. More importantly, our results uncover a simple but powerful mechanism to exert vertical market power. Using collaborative incentives that link the reward to the performance of the different SBUs, vertically integrated firms induce higher prices and achieve higher profit. These observable outcomes are similar to those of the foreclosure argument. Closer inspection, however, reveals that our downstream SBU behaves less competitively, increasing downstream prices at the expense of market share rather than taking advantage of the rivals' higher costs, as in the foreclosure argument. Moreover, the upstream SBU behaves more competitively and benefits from the higher prices downstream.

The remainder of the paper is organised as follows. Section 2 outlines the agent-based simulation model. Section 3 presents the results, which are extended in Section 4. A short discussion follows in Section 5.

\section{The Computational Model}

\subsection{General Setting}

The model incorporates key features of energy markets in the short-run. Consider two sequential, oligopolistic markets, a "wholesale" and a "retail" market.

\footnotetext{
${ }^{6}$ Broad incentives could also obstruct learning since it is more difficult to identify the most successful business strategies.
} 
They can represent a wholesale and a retail electricity market. Alternatively, one can think of wholesale gas and electricity markets, whereby gas sold in the gas market is an input for the generation of electricity. In the wholesale market, there are $A$ wholesalers that sell energy to $B$ retailers. These, in turn, re-sell this energy in the end-user market. ${ }^{7}$ Marginal costs are assumed to be constant throughout and normalised to 0 for simplicity. There are no transmission constraints or storage.

Firms are assumed to be capacity constrained. Generators, for example, are limited by the aggregated maximum capacity of their power plants. Wholesale gas sales are also typically constrained by long-term contracts signed between gas producers and shippers, together with high penalties to discourage overutilization of the network. As a stylization to isolate the effects emerging from vertical incentives, we focus on the situation in which capacity is equal across tiers (i.e. there are no particular bottlenecks in the supply chain). Moreover, firms in each tier are assumed to be identical. Hence, if one denotes market capacity as $K$, the individual wholesaler capacity is $K^{w}=\frac{K}{A}$ and that of retailer $K^{r}=\frac{K}{B}$.

\subsection{Market Rules}

Goods are traded repeatedly along the value chain (Figure 1). In a given round $t$, two uniform price auctions take place, first at the retail and then at the wholesale level, following the netback pricing sequence. In each market $i, i \in\{r, w\}$, trading occurs as follows. Suppliers simultaneously submit single price bids at which they are willing to sell (up to) their capacity, starting from 0 and up to $\bar{P}^{i}(t)$, a maximum level for each market described below. An independent auctioneer determines the uniform market price $P^{i}(t)$ by intersecting the ad hoc supply function with the corresponding demand curve, $Q^{i}(t)$. The independent auctioneer assigns full capacity, $q_{j}^{i}(t)=K^{i}$, to the $m$ sellers with bids below the market price; the remaining capacity, $q_{j}^{i}(t)=Q^{i}(t)-m K^{i}$, to the sellers with bids equal to the market price $;^{8}$ and zero sales, $q_{j}^{i}(t)=0$, to those submitting above the market price. The price and the individual quantities are then communicated independently to each supplier.

We follow the usual simplification of modeling retail demand as fully inelastic. The literature has established the extremely low price elasticity of short term electricity demand, originating among others from the lack of real-time metering systems (e.g. Stoft 2002). In particular, the inelastic market demand $Q^{r}(t)$ is drawn, independently in each round, from a uniform distribution in $\left[\bar{Q}^{r}-\varepsilon, \bar{Q}^{r}+\varepsilon\right]$, where $\bar{Q}^{r}$ is the expected end-user demand and $\varepsilon$ accounts for the small uncertainty typical in day-ahead forecasting. We assume that there always is overall overcapacity, $\bar{Q}^{r}+\varepsilon<K$, consistent with the normal operations

\footnotetext{
${ }^{7}$ Although relevant in the medium term, we do not deal with entry and exit of firms, variation in expected end-user demand or capacity expansion.

${ }^{8} \mathrm{In}$ case of a tie, the selling firm is selected randomly.
} 


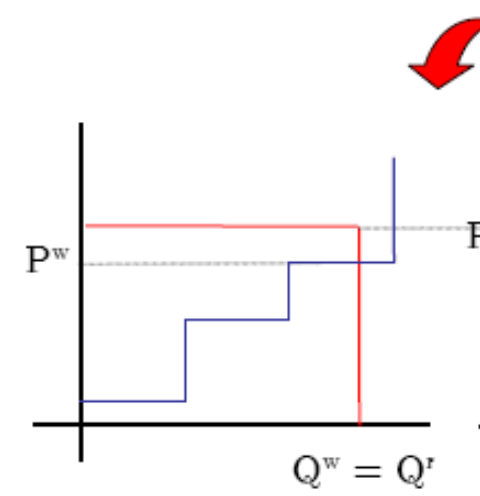

Wholesale Market

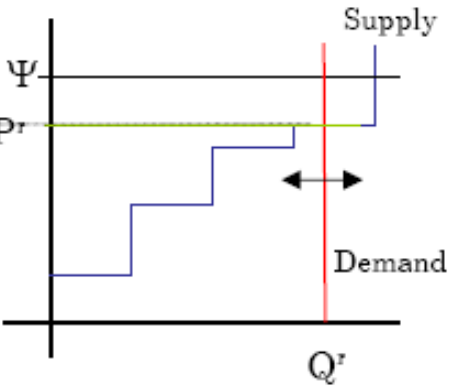

Retail Market

Figure 1: Sequential clearing of the market simulation.

of most de-regulated energy markets. ${ }^{9}$ Hence, our model excludes blackouts due to extreme weather or technical failure.

Possible retail prices are bounded between $(0, \Psi]$, with $\Psi$ being the maximum reasonable end-user price, and therefore $\bar{P}^{r}(t)=\Psi .{ }^{10}$ Retail commitments are honoured with purchases in the wholesale market. The retailers' aggregated demand curve in the wholesale market is equal to the market demand if the price is below the retail price, $Q^{w}(t)=Q^{r}(t)$ if $P^{w}(t) \leq P^{r}(t)$, and zero otherwise, $Q^{w}(t)=0$ if $P^{w}(t)>P^{r}(t)$. Accordingly, wholesalers submit bids bounded between $\left(0, P^{r}(t)\right]$ and $\bar{P}^{w}(t)=P^{r}(t)$.

Profits for each firm type are

$$
\begin{aligned}
\pi_{a}^{w}(t) & =P^{w}(t) q_{a}^{w}(t) & & \text { for } a=1 \ldots A \\
\pi_{b}^{r}(t) & =\left[P^{r}(t)-P^{w}(t)\right] q_{b}^{r}(t) & & \text { for } b=1 \ldots B .
\end{aligned}
$$

There are apparently no other multi-tier simulations driven by netback principles in the energy modelling literature. This new method is the paper's main methodological contribution.

\subsection{Vertical Integration and Reward Interdependence}

In the basic model, it is assumed that a wholesaler (without loss of generality, $a=1)$ and a retailer $(b=1)$ are vertically integrated in that they belong to

\footnotetext{
${ }^{9}$ For example, the UK energy system includes a reserve margin of about $20 \%$ of expected peak demand.

${ }^{10}$ This upper price ceiling can be understood as a limit triggering regulatory intervention or the cost of alternative, expensive, peaking load fuels to which the system administrator could switch at short notice if prices exceed $\Psi$.
} 
the same organisational structure (i.e. the same firm). Trading is compulsory and firms are not allowed to price discriminate or set an internal transfer price. However, the vertically integrated firm can influence its traders' decisions with incentives depending not only on their own SBU profits, but also on those of the other SBUs,

$$
\begin{aligned}
\Omega_{1}^{w}(t) & =(1-\alpha) \pi_{1}^{w}(t)+\alpha \pi_{1}^{r}(t) \text { and } \\
\Omega_{1}^{r}(t) & =(1-\alpha) \pi_{1}^{r}(t)+\alpha \pi_{1}^{w}(t),
\end{aligned}
$$

where $\alpha=\{0, .01, .02, \ldots, .5\}$ parameterises the "reward interdependence" (Wageman and Baker) between the two vertically related SBUs. A small $\alpha$ represents narrow incentives, which become broader for growing $\alpha$. Note that for $\alpha=0$, $\Omega_{1}^{w}(t)=\pi_{1}^{w}(t)$ and $\Omega_{1}^{r}(t)=\pi_{1}^{r}(t)$, and SBUs trade as if they were independent. For tractability and realism, the model is restricted to the case in which SBUs are rewarded predominantly on the basis of their own performance (i.e. $\alpha \leq 0.5)$.

Managers in the non-integrated firms do not have reward interdependences, so their incentives are correlated to their own unit performance,

$$
\Omega_{j}^{i}(t)=\pi_{j}^{i}(t) \text { for } i=\{w, r\} \text { and } j \neq 1 .
$$

\subsection{Bidding and Behavioural Learning}

The feasible price offer domain for each firm is approximated by a discrete grid consisting of a fixed number of possible actions (independent of $t$ ). In each trading period, suppliers choose among $S^{i}$ possible prices, equally spaced between the minimum and the maximum price offer, $\left(0, \bar{P}^{i}(t)\right]$. Hence, the set of possible actions, $A^{i}$ at a tier $i$ in a period $t$ is given by

$$
A^{i}(t)=s *\left(\frac{\bar{P}^{i}(t)}{S^{i}}\right) \quad \text { for } s=1, \ldots, S^{i} .
$$

Notice that in the wholesale market, the set of possible prices changes over time. In both markets, actions with a lower $s$ are more competitive or closer to the marginal costs.

Each trader plays each possible action with a given likelihood or "propensity", $r_{j, s}^{i}$. The probability that an agent $j$ plays an action $s$ is given by its propensity divided by the sum of the propensities of all possible actions,

$$
p_{j, s}^{i}(t)=\frac{r_{j, s}^{i}(t)}{\sum_{s=1}^{S^{i}} r_{j, s}^{i}(t)} .
$$

Propensities for all actions are initialised to the firms' maximum profit, $r_{j, s}^{i}(1)=$ $\Psi K^{i}$ for all $s$ and $i$, so that all actions have the same initial probability, $p_{j, s}^{i}(1)=$ $\frac{1}{S^{i}}$ for all $s$ and $i$. 
At the end of each round, traders reinforce the selected action, $k$, through an increase in its propensity equivalent to the performance, $\Omega_{j}^{i}(t)$. Moreover, actions that are similar, $k-1$ and $k+1$, are also reinforced, by $\Omega_{j}^{i}(t) *(1-\delta)$ where $0<\delta<1$ ("persistent local experimentation" in the terminology of Roth and Erev). All propensities are discounted by $\gamma$ ("gradual forgetting"), and actions whose probability falls below a certain threshold are removed from the space of choice ("extinction in finite time"). Summarising, the pre-extinction propensities $r_{j, s}^{i \prime}$ are

$$
r_{j, s}^{i \prime}(t)=\left\{\begin{array}{lr}
(1-\gamma) r_{j, s}^{i}(t-1)+\Omega_{j}^{i}(t) & \text { if } s=k \\
(1-\gamma) r_{j, s}^{i}(t-1)+(1-\delta) \Omega_{j}^{i}(t) \quad \text { if } s=k-1 \text { or } s=k+1 \\
(1-\gamma) r_{j, s}^{i}(t-1) & \text { if } s \neq k-1, s \neq k \text { and } s \neq k+1,
\end{array}\right.
$$

and the final propensities, corrected by the extinction feature, are

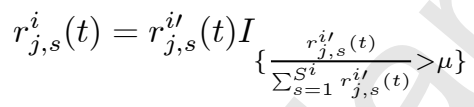

where $I$ is an indicator function that takes value 1 if the condition between brackets is satisfied and zero otherwise.

\subsection{Simulation Parameters}

In the first instance, industry structure is simplified to consist of two wholesalers and three retailers (i.e. $A=2 ; B=3$ ). Remember that the two vertically integrated entities are denoted by $a=1$ and $b=1$. Total capacity is set to $K=300$ so that the individual capacity of a wholesaler is $K^{w}=150$ and of a retailer $K^{r}=100$. Expected market demand is $\bar{Q}^{r}=240$ and $\varepsilon=5$, and hence there is an expected excess capacity of $20 \%$ with about $5 \%$ uncertainty in the day-ahead forecasted demand, approximately of the magnitude observed in energy markets. The end-user reasonable price ceiling is set at $\Psi=200$.

We study fifty-one reward interdependence cases $\alpha=\{0, .01, .02, .03, \ldots, .50\}$ with 50 simulation runs consisting of 500 periods each. The data consists of averages for the last 200 periods for each run and case. These represent long term stationary values to which the three markets converge, based on the Roth and Erev reinforcement parameters. ${ }^{11,12}$

\section{Results}

This section describes the simulation results. We report first the results on market prices and firm profits. We then turn to the analysis of firm behaviour,

\footnotetext{
${ }^{11}$ For each level of reward interdependence $(\alpha)$, the one-lag with trend Augmented DickeyFuller test-statistics for both wholesale and retail price series are lower than -10 . Given that the $95 \%$ critical value is -3.43 , the null hypothesis of non-stationarity is always rejected.

12 The Roth and Erev parameters used throughout are $\gamma=0.01, \delta=0.5$ and $\mu=0.0005$.
} 


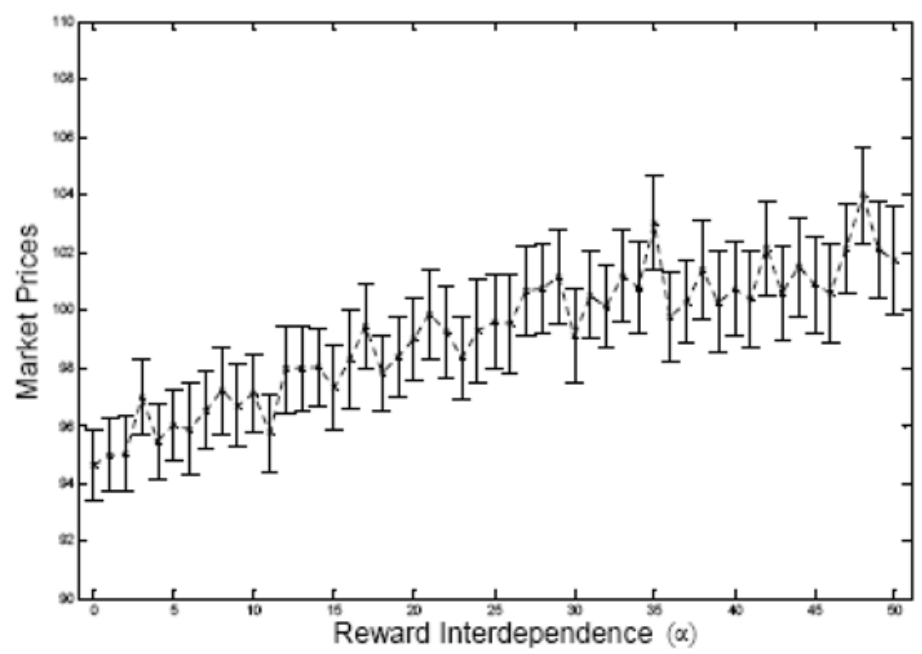

Figure 2: Wholesale prices

reporting the individual price setting frequencies and latent probability distributions. Based on the individual behaviour analysis, we provide in the last subsection an intuitive explanation of our market outcomes.

\subsection{Market Prices and Profits}

Figures 2 and 3 report the $95 \%$ mean confidence intervals of simulated prices in the two sequential markets. They present the relationship between reward interdependence ( $\alpha$, on the horizontal axis) and the wholesale and retail prices ( $P^{w}$ and $P^{r}$, on the vertical axis), respectively. As shown by Figure 2, wholesalers coordinate on higher prices as $\alpha$ grows. The lack of reward interdependence between the integrated wholesaler and retailer $(\alpha=0)$ results in an average wholesale price of approximately 95 monetary units, which increases to about 102 units for overall performance-based incentives $(\alpha=.50)$. That is, if the SBUs of the vertically integrated firm traded as if they were independent, wholesale market prices would be lower.

Figure 3 shows that retail prices are also increasing in the level of reward interdependence. When $\alpha=0$, the simulation produces an average price of about 132; for $\alpha=.50$ it is about 148. As a result, the expected absolute size of the resource rent shared by the two tiers $\left(=P^{r} \bar{Q}^{r}\right)$ also increases. The proportion accruing to the retailers, however, does not increase. Retail prices increase only to compensate the higher wholesale prices. Increasing wholesale prices with constant production costs results in a higher proportion of the rent staying with the wholesale duopoly.

As a consequence, $\alpha$ influences both the profits of the vertically integrated 


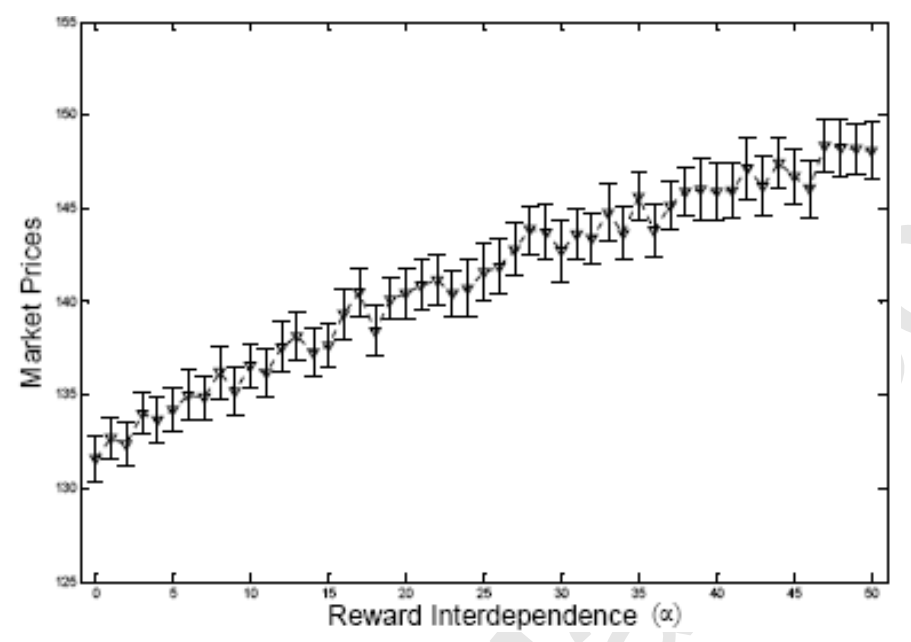

Figure 3: Retail prices.

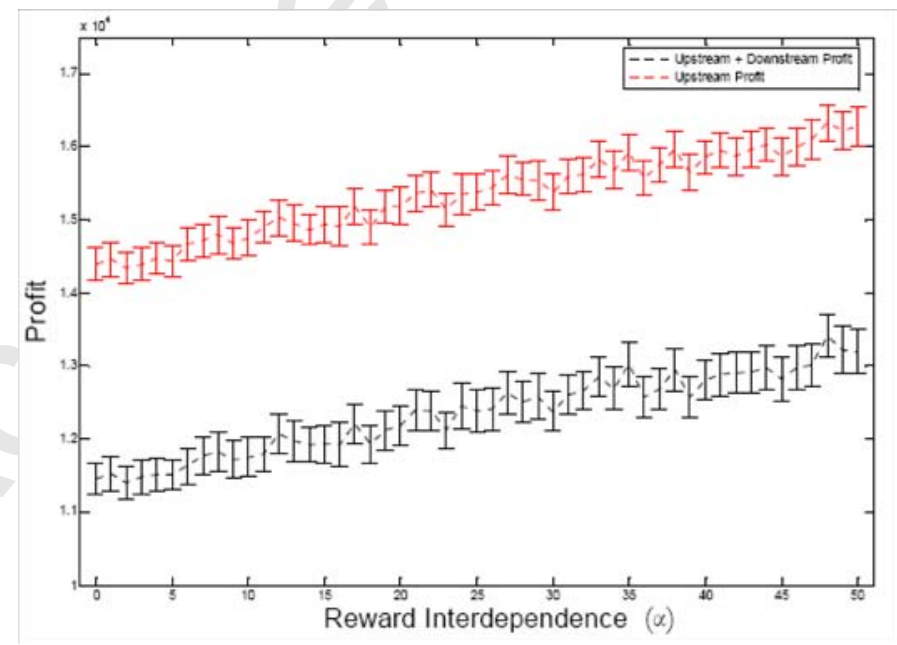

Figure 4: Profit, vertically integrated firm. 
firm and its two SBUs (Figure 4). Although broader vertical incentives do not increase the profits of its retail unit, they increase those of its wholesale unit. The resulting overall corporate profit $\left(\pi_{1}^{w}+\pi_{1}^{r}\right)$ is clearly increasing from about 14,300 monetary units to over 16,000 . Thus, there is a positive relationship between vertical reward interdependence across the two strategic business units, the firm's overall profit and the concentration of profit upstream.

Summarising, as in Ordover et al., wholesale and retail prices increase as a result of vertical integration. Indeed, the vertically integrated firm achieves higher profit by using rewards based on overall firm performance. With this type of reward interdependence, prices are higher than if the two business units had been independent.

In order to provide an explanation for these results one needs to explore the individual behaviour of firms, to which we turn next.

\subsection{Price-setting Behaviour}

In a uniform auction, prices are determined by the last bid on the merit order, and therefore being a marginal seller is a necessary condition to influence prices. Hence, the frequency with which each firm takes the marginal price-setting position on the supply merit order represents one dimension of its predisposition to exert market power (at the expense of market share).

The vertical axes in Figures 5 and 6 provide averages over the frequencies with which each market player sets the price in the 200 end-of-simulation periods averaged across the 50 simulation runs. An increase in the reward interdependence in the vertically integrated firm creates two simultaneous effects. On the one hand, the proportion of trading periods in which the wholesale unit sets prices goes down from about $50 \%$ when $\alpha=0$ to less than $40 \%$ when $\alpha=0.5$ (Figure 5). As in Ordover et al., vertical integration provides incentives for the wholesale unit to concede market power upstream and, as a result, for the competitor to push up the wholesale price.

On the other hand, the proportion of trading periods in which the integrated retail unit is price-setting increases from $33 \%$ when $\alpha=0$ to about $50 \%$ for $\alpha=0.5$ (Figure 6). As a result, there is a negative relationship between $\alpha$ and the retail unit's market share, which is at odds with Ordover et al.'s findings.

\subsection{Latent Intensity of Competition}

A similar behaviour can be identified in the $S^{i}$ end-of-simulation individual latent probability distributions from which agents choose bids, depicted in Figures 7 and 8. The concentration of probabilities is largely invariant across a large number of periods once the market reaches convergence, so the distributions on the last trading period are an indication of the firms' long-term mixed strategies.

On the horizontal axes, strategies are identified with numbers ranging from 1 for the more competitive to 100 for the highest possible bid. Cumulative probabilities for the two tiers are calculated on the vertical axes for each element of the strategy space. The curves summarise the cumulative bidding 


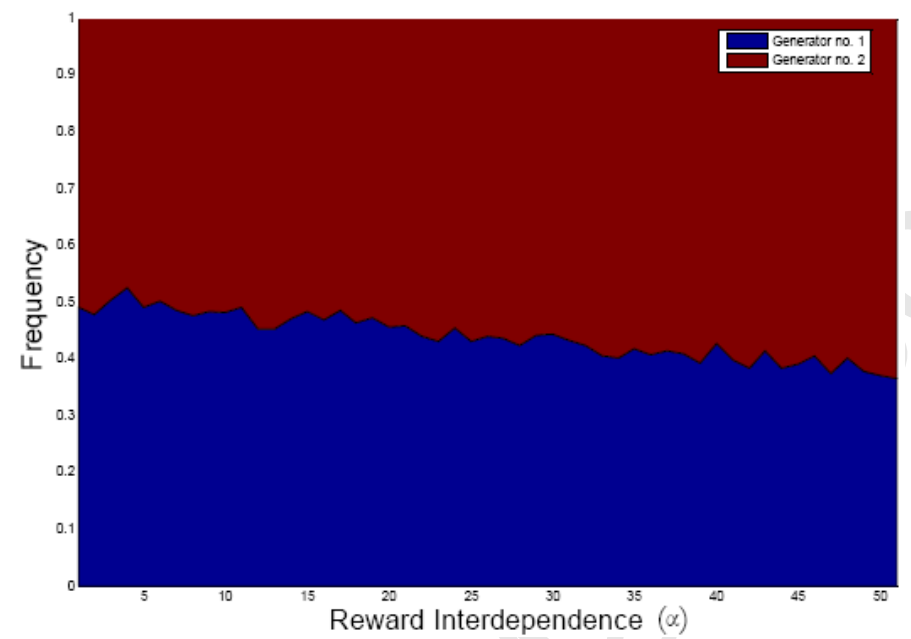

Figure 5: Wholesalers' price-setting frequencies.

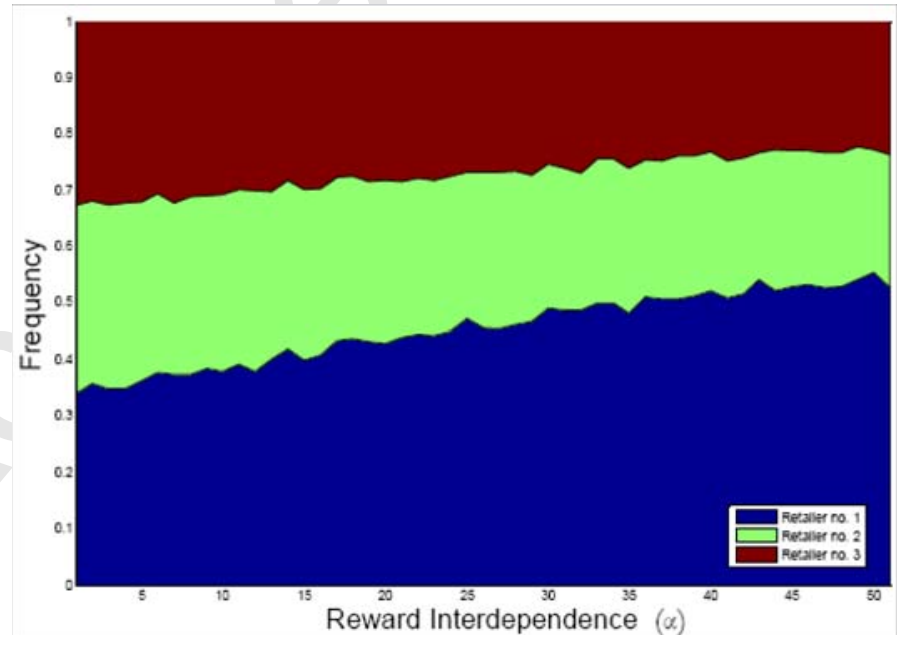

Figure 6: Retailers' price-setting frequencies. 


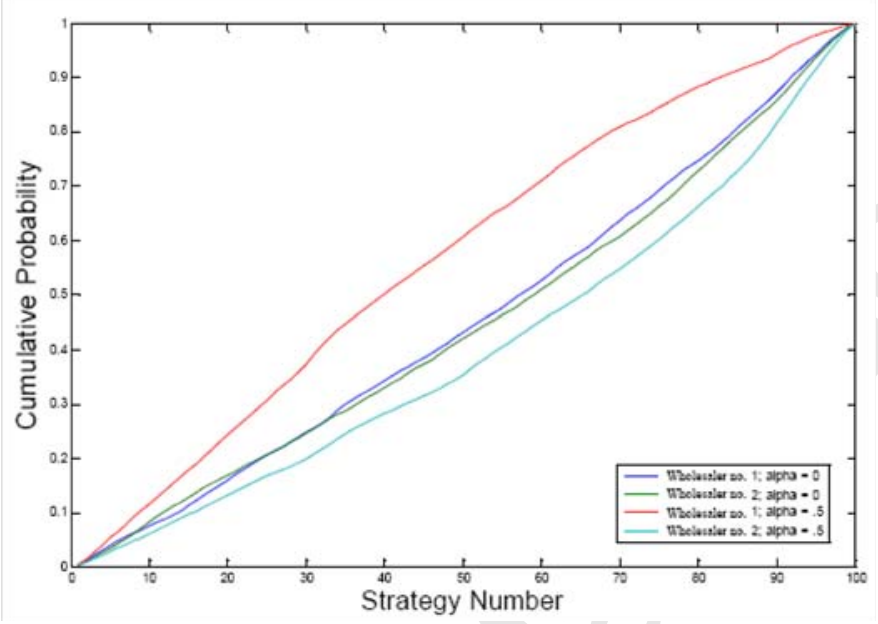

Figure 7: End of simulation distribution of strategies of wholesalers.

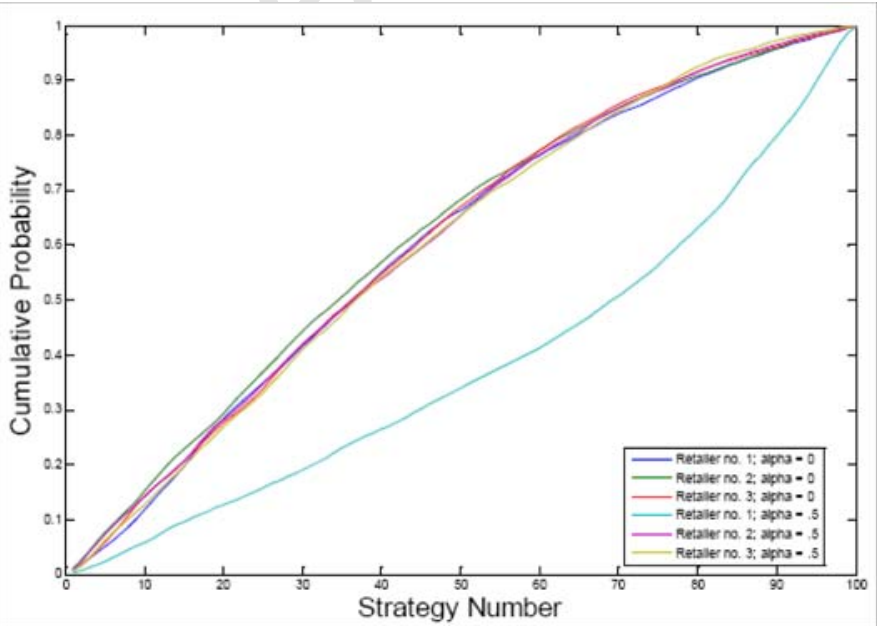

Figure 8: End of simulation distribution of strategies of retailers. 
probabilities for $\alpha=0$ and $\alpha=0.5$, averaged across the 50 simulation runs. In all cases, probabilities concentrated on lower and higher strategies result in the agents behaving more and less competitively, respectively. That is, curve movements to the upper-left and lower-right corners are indications of more and less competition, respectively. ${ }^{13}$

The figures offer a number of insights linking individual probability distributions to market outcomes. First, the wholesalers' distributions are very similar under $\alpha=0$ but become different under $\alpha=0.5$ (Figure 7). Reward interdependence incentives in the vertically integrated firm have the effect of making the integrated wholesaler's bids more competitive (upper-left movement). Moreover, the rival wholesaler's prior is slightly less competitive (movement to the lower-right). Market power is concentrated on the non-integrated wholesaler. Second, probability distributions on the retailer side are similar for all firms under $\alpha=0$ (Figure 8). However, when $\alpha=0.5$, the integrated retailer tends to exert more market power than its competitors (movement to the lower-right).

\subsection{Firm Learning, Behaviour and Market Outcomes}

Through their dynamic trading interaction, firms learn to prioritise those bidding strategies that achieve higher payoffs and choose them more often. Each firm's price setting frequency is related to the strategy reinforcement, and once marginal supply and demand patterns are established, price regularities follow. The results suggest a link between reward interdependence, firm learning, trading behaviour and market outcomes.

As reward interdependences increase, the retail SBU submits higher bids, sets prices more often and increases them markedly, albeit at the expense of market share. However, wholesale prices are bounded below retail prices due to the netback procedure. A higher retail price shifts up the wholesale demand curve and, thus, provides more scope for higher wholesale prices. Then, the wholesale SBU trades more often on the baseload, making it easier for its opponent to increase prices. As a consequence, the integrated firm improves its upstream market share and profitability, and this has a positive effect on the total profits of the vertically integrated firm.

Our results yield prices that are superficially equivalent to those of foreclosure, which, by construction, cannot occur in our setting. We uncover a different mechanism to exert vertical market power in which the downstream SBU behaves less competitively, gives up market share and pushes up retail prices, rather than benefit from its' rivals' higher costs, as in Ordover et al. The identification of this mechanism is this paper's main economic policy contribution.

\footnotetext{
${ }^{13}$ Notice that how competitive the strategies are is determined with respect to the maximum bid, and therefore more competitive strategies could translate into higher absolute bids.
} 


\begin{tabular}{llll}
\hline \hline & $\mathbf{P}^{g}$ & $\mathbf{P}^{e}$ & $\mathbf{P}^{c}$ \\
\hline Separation $(\boldsymbol{\alpha}=\mathbf{0})$ & 59 & 83 & 124 \\
\hline \hline Shipper-Generator $(\boldsymbol{\alpha}=. \mathbf{5})$ & 63 & 93 & 125 \\
& $+6.77 \%$ & $+12.04 \%$ & $+0.88 \%$ \\
\hline Shipper-Retailer $(\boldsymbol{\alpha}=. \mathbf{5})$ & 67 & 95 & 144 \\
& $+15 \%$ & $+14.45 \%$ & $+16.12 \%$ \\
\hline Generator-Retailer $(\boldsymbol{\alpha}=. \mathbf{5})$ & 63 & 88 & 136 \\
& $+6.77 \%$ & $+6.02 \%$ & $+9.67 \%$ \\
\hline \hline
\end{tabular}

Table 1: Average Prices for a market with two gas shippers, three electricity generators, and four electricity retailers.

\section{Extensions}

Generators may buy their inputs in wholesale markets one step up in the value chain. For example, gas sold in the wholesale market may be an input for the generation of the electricity traded in the wholesale electricity market that, in turn, is sold to end users in the retail market. This section extends the previous analysis from two to three tiers. We also analyse whether the results depend on the position of the vertically integrated SBUs in the value chain and on market concentration levels.

\subsection{Three-tier Markets}

Consider three sequential energy markets, with the same characteristics as before. ${ }^{14}$ Suppose that in the gas market there are two upstream natural gas shippers that sell gas to three electricity generators. These generators buy gas to produce electricity and sell it in the wholesale electricity market to four electricity retailers, who re-sell in the end-user market.

New simulations analyse reward interdependences between a gas shipper and a generator plus those between a gas shipper and a retailer and a generator and a retailer, keeping all other parameters constant. Table 1 summarises results for $\alpha=0$ and $\alpha=.5$ in these new simulations.

Similar to the previous results, reward interdependences between a natural gas shipper and an electricity generator result in an increase in both wholesale gas and electricity markets. Wholesale gas prices, $P^{g}$, increase from an average of 59 for $\alpha=0$ to 63 when $\alpha=.5(+6.77 \%)$ whereas wholesale electricity prices, $P^{e}$, increase from 83 to $93(+12.04 \%)$. Interestingly, there is a negligible change in retail electricity prices, $P^{c}(+0.88 \%)$, and therefore end-users would not be hurt here. Market prices seem to indicate that retailers are particularly damaged from reward interdependences between a gas shipper and a generator.

Two complementary findings emerge from the simulated consequences of reward interdependences linking the fortunes of a natural gas shipper and a

\footnotetext{
${ }^{14}$ See the working paper version of the paper for more details on the model and results, as well as for additional figures, for this three-tier case.
} 


\begin{tabular}{llll}
\hline \hline & $\mathbf{P}^{g}$ & $\mathbf{P}^{e}$ & $\mathbf{P}^{c}$ \\
\hline Separation $(\boldsymbol{\alpha}=\mathbf{0})$ & 71 & 100 & 143 \\
\hline \hline Shipper-Generator $(\boldsymbol{\alpha}=. \mathbf{5})$ & 73 & 108 & 143 \\
& $+2.81 \%$ & $+8 \%$ & $0 \%$ \\
\hline \hline
\end{tabular}

Table 2: Average Prices for a market with two gas shippers, two electricity generators, and two electricity retailers.

retailer. First, retail prices increase from an average of 124 for $\alpha=0$ to 144 when $\alpha=.5(+16.12 \%)$, compared to a negligible change when $\alpha$ links a shipper and a generator. Reward interdependence induces the retailer to implement a less competitive-mixed strategy through which the firm becomes price setting more often with the retail price increasing steadily.

Secondly, wholesale prices increase, too. The effect on retail prices moves up in the value chain. It translates into higher wholesale electricity and gas prices from about 83 to $95(+14.45 \%)$ and 59 to $67(+15 \%)$, respectively. Reward interdependences hurt end users in this case. Although the generators' probability priors and trading behaviour change little, the integrated shipper becomes more competitive and facilitates the exertion of market power by its upstream rival, which leads to a wholesale electricity-gas difference similar to the initial case. Moreover, by construction, higher retail prices widen the range within which wholesale electricity prices are determined. With a constant number of bidding strategies, $S^{i}$, similar generators' probability distributions result in higher wholesale prices as the retail price increases.

The simulations assuming integration between a generator and a retailer show increases in wholesale electricity and retail prices $(+6.02 \%$ and $+9.67 \%)$. The downstream unit manages to leverage its overall revenue and implement a more collusive mixed strategy that expands the base for higher wholesale electricity prices. The upstream unit, on the other hand, bids more often on the base-load part of the supply curve, with the other generators setting (higher) prices. It is interesting to note how the non-integrated gas shippers capture a large proportion of the rent through a higher wholesale natural gas increase of $6.77 \%$.

\subsection{Symmetric Market Structure across Tiers}

In the previous analysis, market structure remained progressively less concentrated. The vertical foreclosure literature suggests that higher upstream concentration is an important element of the firms' ability to exert vertical market power. We check this result in our setting, through a symmetric-across-tiers simulation.

Table 2 summarises market prices for the case in which there are two firms in each tier. Vertical integration between a shipper and a generator leads, as in the asymmetric case, to higher wholesale electricity and natural gas prices but not higher end user prices. Higher prices with increasing $\alpha$, therefore, hinge on 
the market clearing sequence rather than on market structure asymmetries. ${ }^{15}$

\section{Discussion}

The existence of interdependences between vertically related SBUs has become a bedrock in the business strategy literature, yet we know relatively little about the forces shaping these interdependences and their effects. A set of agentbased simulations identifies one such effect in the de-regulated energy industry. Reward interdependences between SBUs lead to trading coordination and higher prices. Under tight reward interdependence structures, vertically integrated firms increase the scope for upstream profits. This leads to strategic behaviour with the superficial appearance of foreclosure, but based on a quite different principle. This paper adds to the preceding literature in at least three ways.

Methodologically, we are not aware of any other multi-tier energy simulations driven by netback principles in the literature. The financial dependence between electricity and natural gas markets does not seem to be captured by the classical models of vertical foreclosure, where causal pricing relationships are sequential from the upstream to the downstream segment.

The second contribution relates to the literature on the sources of vertical market power in the energy industry (e.g. Bushnell et al. 2005, Granitz and Klein 1996, Kühn and Machado 2004). The simulations suggest a new mechanism to solve the puzzle of how vertical market power appears in some energy markets where it should not. The downstream unit submits higher bids and increases retail prices. As a result, the range of possible upstream prices also increases. Then, the upstream unit stays on the baseload part of the supply curve, increases its market share and allows its opponent to increase wholesale prices. Hence, vertical market power emerges in a compulsory, uniform price auction without trading internalisation or price discrimination.

Thirdly, the research identifies a link between internal incentive structures, SBU behaviour and firm performance. Reward interdependence has been shown to be an instrument leading to market power via higher vertical SBU coordination. Ways in which reward interdependences can be articulated include direct bonuses and stock options, and casual evidence indicates that these are widespread in the energy industry. It is interesting to note that such reward interdependence contracts are internal to the firm and, hence, normally fall outside the scope for regulatory intervention. Whether firms use them explicitly as a way of aligning their interests to those of their SBU employees is an interesting question for future empirical work.

\footnotetext{
${ }^{15}$ Results under two symmetric firms in two tiers and three symmetric firms in three tiers are qualitatively equivalent to the case of two symmetric firms in three tiers.
} 


\section{References}

[1] Bushnell, J., Saravia, C., Mansur, E., 2005. Vertical arrangements, market structure, and competition: An analysis of restructured U.S. electricity markets. UC Energy Institute CSEM Working Paper.

[2] Chatterjee, S., Lubatkin, M., Schoenecker, T., 1992. Vertical strategies and market structure: A systematic risk analysis. Organization Science 3, $138-156$.

[3] Choi, J. P., Yi, S. S., 2000. Vertical foreclosure with the choice of input specifications. RAND Journal of Economics 30, 717-743.

[4] Finon, D., Midttun, A., 2004. Reshaping European Gas and Electricity Industries. Amsterdam: Elsevier Science.

[5] Gaudet, G., van Long, N., 1996. Vertical integration, foreclosure and profits in the presence of double marginalisation. Journal of Economics and Management Strategy 5, 409-432.

[6] Granitz, E., Klein, B., 1996. Monopolization by "Raising Rivals' Costs": The Standard Oil case. Journal of Law and Economics 39, 1-47.

[7] Gulati, R., Lawrence, P. R., Puranam, P., 2005, Adaptation in vertical relationships: Beyond incentive conflict. Strategic Management Journal $5,415-440$.

[8] Gulati, R., Singh, H., 1998. The architecture of cooperation: Managing coordination costs and appropriation concerns in strategic alliances. Administrative Science Quarterly 43, 781-794.

[9] Harrigan, K. R., 1984. Formulating vertical integration strategies. The Academy of Management Review 9, 638-652.

[10] Harrigan, K. R., 1986. Matching vertical integration strategies to competitive conditions. Strategic Management Journal 7, 535-555.

[11] Hart, O., Tirole, J., 1990. Vertical integration and market foreclosure. Brookings Papers on Economic Activity: Microeconomics 1990, 205285.

[12] Holmstrom, B., 1982. Moral hazard in teams. Bell Journal of Economics $13,324-340$.

[13] Hunger, D., 2003. Analyzing gas and electric donvergence mergers: A supply curve is worth a thousand words. Journal of Regulatory Economics 24, 161-173.

[14] Joskow, P., 2000. Deregulation and regulatory reform in the U.S. electric power sector. In: Peltzman, S., Winston, C. (Eds.). Deregulation of Network Industries: What is Next?. Washington, D.C.: Brookings Press, 119-124.

[15] Kretschmer, T., Puranam, P., 2004. Exploiting Synergies in Complex Organizations: When do Collaborative Incentives Create Value? Forthcoming in Organization Science. 
[16] Kühn, K.-U., Machado, M., 2004. Bilateral market power and vertical integration in the Spanish electricity spot market. CEPR Working Paper, DP4590.

[17] Lawrence, P. R., Lorsch, J. W., 1967. Differentiation and integration in complex organisations. Administrative Science Quarterly 12, 1-48.

[18] Ma, C. A., 1997. Option contracts and vertical foreclosure. Journal of Economics and Management Strategy 6, 725-753.

[19] Mahoney, J. T., 1992. The choice of organizational form: Vertical financial ownership versus other methods of vertical integration. Strategic Management Journal 13, 559-584.

[20] Moxnes, E., 1987. The dynamics of interfuel substitution in the OECDEurope industrial sector. In: Golombek, R. Hoel, M., Vislie, J. (Eds). Natural Gas Markets and Contracts. Contributions to EconomicAnalysis. Amsterdam: North Holland.

[21] Ordover, J. A., Saloner, G., Salop, S., 1990. Equilibrium vertical foreclosure. The American Economic Review 80, 127-142.

[22] Petersen, T., 1992. Individual, collective and systems rationality in work groups: Dilemmas and market-type solutions. American Journal of Sociology 98, 469-510.

[23] Rey, P., Tirole, J., 2004. A primer on foreclosure. In: Armstrong, M., Porter, R. (Eds.). Handbook of Industrial Organization 3, 2145-2220. New York: North Holland..

[24] Roth, A., Erev, I., 1995. Learning in extensive form games: Experimental data and simple dynamic models in the intermediate term. Games and Economic Behavior 8, 164-212.

[25] Salinger, M., 1988. Vertical mergers and market foreclosure. Quarterly Journal of Economics 77, 345-356.

[26] Stern, J. P., 1998. Competition and Liberalization in European Gas Markets: A Diversity of Models. London: Royal Institute of International Affairs.

[27] Stoft, S., 2002. Power System Economics: Designing Markets for Electricity. Piscataway, NJ, U.S.: IEEE Press.

[28] von der Fehr, N., Harbord, D., 1993. Spot market competition in the UK electricity industry. The Economic Journal 103, 531-546.

[29] Wageman, R., Baker, G., 1997. Incentives and cooperation: The joint effects of task and reward interdependence on group performance. Journal of Organizational Behavior 18, 139-158.

[30] Williamson, O., 1975. Market and Hierarchies. New York: Free Press.

[31] Zander, A., Wolfe, D., 1964. Administrative rewards and coordination among committee members. Administrative Science Quarterly 9, 50-69. 